\title{
Erratum to: Implantation of autologous muscle-derived stem cells in treatment of fecal incontinence: results of an experimental pilot study
}

\author{
M. Romaniszyn ${ }^{1} \cdot$ N. Rozwadowska ${ }^{2} \cdot$ A. Malcher $^{2} \cdot$ T. Kolanowski ${ }^{2} \cdot$ P. Walega ${ }^{1} \cdot$ M. Kurpisz $^{2}$
}

Published online: 27 October 2015

(C) Springer-Verlag Italia Srl 2015

\section{Erratum to: Tech Coloproctol DOI 10.1007/s10151-015-1351-0}

Owing to an unfortunate mistake at Springer's end, the original article was published with errors which are corrected with this erratum. The authors are not responsible for this procedural lapse.

1. In "Methods and Materials" section, the paragraph starting with "After preparation of the site...." should read as given below.

After preparation of the site, local anesthesia was administered (1\% lidocaine s.c.) and the suspension of $10^{8}$ myogenic stem cells per ml in DMEM with $1 \%$ human albumin was administered deep into the EAS under ERUS guidance. Total volume of the suspension (about $3 \mathrm{ml}$ ) was injected on entire circumference of the external sphincter muscle ring (several injections about $1 \mathrm{~cm}$ apart). In patients with a confirmed EAS defect, the total volume of the suspension was divided into three 1-ml portions: $1 \mathrm{ml}$ was injected on both sides of the muscle scar, one was applied on the remaining circumference of external sphincter muscle ring (injections about $1 \mathrm{~cm}$ apart), and the last portion was injected directly into the scar, so that the bolus of injected fluid had direct contact with healthy muscle tissue, creating a "bridge" between muscle ends, across the scar. Patients went home the same day.

2. In "Results" section, the citation for Fig. 3 should be deleted from the second sentence of the first paragraph. The citations of Fig. 4 in the first sentence and Fig. 5 in the last sentence of the fourth paragraph should read as Figs. 3 and 4, respectively.

3. In addition, Fig. 5 should be numbered as Fig. 12 and Figs. 6 to 12 should be renumbered as Figs. 5 to 11 . The figure citations should be changed in the text as well.

4. The captions of Figs. 7 and 8 were swapped and hence corrected.

The original publication has also been updated.

The online version of the original article can be found under doi:10.1007/s10151-015-1351-0.

\footnotetext{
M. Romaniszyn

m.romaniszyn@mp.pl

kurpimac@man.poznan.pl

1 3rd Department of General Surgery, Jagiellonian University Medical College, ul. Pradnicka 35-37, 31-202 Kraków, Poland

2 Department of Reproductive Biology and Stem Cells, Institute of Human Genetics, Polish Academy of Science, Strzeszynska 32, 60-479 Poznan, Poland
}

$\triangle$ M. Kurpisz 